\title{
1 Landscape drivers and effectiveness of pest control by insectivorous birds in a
}

2 landscape-dominant woody crop

4 Authors: Carlos Martínez-Núñez ${ }^{1 *}$ Pedro J. Rey ${ }^{1,2}$, Antonio J. Manzaneda ${ }^{1,3}$, Daniel

5 García $^{4}$, Rubén Tarifa ${ }^{5}$, José L. Molina ${ }^{1}$ and Teresa Salido ${ }^{1}$.

$7{ }^{1}$ Dept. Biología Animal, Biología Vegetal y Ecología, Universidad de Jaén. E-23071 Jaén,

8 Spain.

$9 \quad{ }^{2}$ Instituto Interuniversitario del Sistema Tierra de Andalucía, Universidad de Jaén, E-23071

10

$11{ }^{3}$ Centro de Estudios Avanzados en Ciencias de la Tierra, Energía y Medio Ambiente.

12

13

14

15

16

17

18

19

Jaén, Spain.

Universidad de Jaén, E-23071 Jaén, Spain.

${ }^{4}$ Departamento de Biología de Organismos y Sistemas, Universidad de Oviedo, y Unidad

Mixta de Investigación en Biodiversidad (CSIC-Uo-PA), C/Catedrático Rodrigo

Uría s/n, E-33006, Oviedo, Asturias, Spain

${ }^{5}$ Estación Experimental de Zonas Áridas. Almería. Spain

*Corresponding author: Carlos Martínez-Núñez [cmnunez@ujaen.es]

Declarations of interest: none 


\section{Abstract}

22 Avian-mediated pest control is a significant ecosystem service with important economic

23 implications. However, there is an overall paucity of experimental information about how

24 landscape simplification affect its current level. Information on pest control by birds is

25 missing in some permanent agroecosystems of worldwide importance, like olive orchards,

26 that dominate vast areas in the Mediterranean region.

27 We assess the effectiveness of insectivorous birds for controlling the two main pest insects

28 in olive orchards and explore the effects of landscape complexity and distance to semi-

29 natural patches on avian insectivore abundance and pest control. For this, we combine bird

30 surveys with field experiments (branch exclusions and pest plasticine models) at the

31 regional scale.

32 Landscape heterogeneity increased the abundance and richness of insectivorous birds,

33 which were also more abundant and diverse in semi-natural patches, compared to the farm

34 olive matrix. Experiments evidenced that pest control by birds (measured as attack rates to

35 plasticine models and pest damage) in the studied olive orchards is negligible, while pests

36 were overall abundant and pest damage was high on most farms. This raises alarms about

37 the status of avian pest control in this agroecosystem.

38 Although landscape heterogeneity increased the abundance/richness of insectivorous birds,

39 and favored some forest species, insectivorous bird abundance seems diluted in relation to

40 prey availability in all landscapes. Thus, pest control by birds seems currently unsuccessful

41 in olive orchards. Our results might be evidencing the loss of an ecosystem service due to a

42 generalized massive decline of common and forest insectivorous birds. 


\section{$44 \quad$ Key message}

45

46

47

48

49

50

51

52 Keywords: Bactrocera oleae, bird assemblages, crop damage, landscape complexity,

53 olive orchard, Prays oleae.
- Olive orchards dominate extensive areas causing important landscape simplification.

- Insectivorous birds are more abundant in semi-natural patches within olive farms.

- Field experiments show a low impact of birds on olive pests and damage.

- Avian-mediated pest biocontrol seems diluted by limited suitable habitat for birds.

- Agri-environmental measures should focus on increasing landscape complexity. 


\section{Introduction}

55 Agricultural intensification is often characterized by monocultures that spread over

56 extensive areas, creating highly homogeneous landscapes (He et al., 2019). Monocultures

57 that dominate vast areas are especially prone to suffer from pest damage (He et al., 2019;

58 Redlich, Martin, \& Steffan-Dewenter, 2018), because spatial and biotic homogenization

59 favors the spread and success of specialist pests and also removes natural habitats that host

60 potential natural enemies (Grab, Danforth, Poveda, \& Loeb, 2018; Rusch et al., 2016). In

61 this sense, only natural enemies that tolerate the micro-environmental conditions of the

62 culture, or that span/forage in large areas, can be effective pest control agents in landscape-

63 dominant cultures. In woody agroecosystems, insectivorous birds can play an important

64 role controlling pest species because the vertical structure of the culture can be alike their

65 natural habitats, they can forage over wide areas and their high metabolic rate forces them

66 to ingest a considerable amount of energy (preys) (e.g. Bael et al., 2008; García, Miñarro \&

67 Martínez-Sastre, 2018; Mols \& Visser, 2007). Consequently, insectivorous birds are

68 important biological agents, proven successful for pest control in some agroecosystems

69 (García, Miñarro \& Martínez-Sastre, 2018; Mols \& Visser, 2007)et al., 2018; Karp et al.,

70 2013). However, there are still numerous agroecosystems of worldwide relevance where

71 the effectiveness of avian mediated pest control and the impact of landscape drivers on it,

72 are unknown (Boesing, Nichols, \& Metzger, 2017).

73 Some landscape components can benefit insectivorous bird communities and mediate their

74 contribution to pest control. For instance, semi-natural patches commonly enhance bird

75 communities and pest control on agroecosystems (Escobar-Ramírez, Grass, Armbrecht, \&

76 Tscharntke, 2019). Also, larger natural habitat fragments often favor higher predation 
77 pressure by birds (Karp et al., 2013), being this pressure usually reduced with distance to

78 the semi-natural patch (Henri et al., 2015; Jordani, Hasui, \& da Silva, 2015). Just recently,

79 some studies have started to experimentally approach landscape effects on this ecosystem

80 service. For instance, Maas, Clough, \& Tscharntke (2013) used exclosures to demonstrate

81 how agroforest in cacao plantations increased yields through pest biocontrol by birds and

82 bats. García, Miñarro, \& Martínez-Sastre (2018), combining experimental insect pest

83 increase and bird exclosures, revealed that forest insectivorous birds, favored by semi-

84 natural woody vegetation around the farms, can control pest outbreaks and diminish

85 damage in apple orchards. Similarly, Koh (2008) used exclusions to show how birds

86 (associated to natural habitat) protected oil palms from herbivores. Other authors have used

87 plasticine models (commonly used to compare attack rates across gradients) to

88

89

90

91

92

93

94

95

96

97

98

99

comparatively approach levels of avian insectivory on pests (reviewed in Bateman,

Fleming, \& Wolfe, 2017). This method have proven useful to explore the effects of agricultural management and landscape heterogeneity on overall pest control (Rusch,

Delbac, Thiéry, \& Thi Ery, 2017), avian pest control in vineyards (Barbaro et al., 2017) or even to find global latitudinal/altitudinal patterns on predation rates (Roslin et al., 2017).

Also, the abundance of insectivorous birds and their predation on plasticine caterpillars has positively been linked to structural heterogeneity (Bereczki, Ódor, Csóka, Mag, \& Báldi, 2014).

Although there is increasing evidence that landscape complexity and semi-natural areas benefit insectivorous birds, still very little mechanistic evidence exists about the landscape drivers affecting insectivorous birds and the top-down cascade implications from insectivores (and other natural enemies) to crop damage. Sometimes, system or 
100

101

102

103

104

105

106

107

108

109

110

111

112

113

114

115

116

117

118

119

120

121

122

species/case-specific effects, such as intraguild predation, lack of effective natural enemies, or functional dilution of the insectivory pressure (due to the low numbers of birds compared to the availability of pests) can lead to low or null impact of natural habitat fragments on pest control (Lewis et al., 2013; Tscharntke et al., 2016). In addition, natural vegetation and landscape complexity can also provide disservices to agroecosystems (e.g. sheltering pests or fruit consumers), but landscape complexity seems to be overall positive, even when accounting for the ecosystem disservices (Gonthier et al., 2019; Linden et al., 2019).

Despite that olive orchards are within the most important agroecosystems worldwide (http://www.fao.org/faostat) and their major insect pests are well-known, we lack experimental information about bird pest control potential in this agroecosystem, and about how it is affected by landscape components. Some studies have addressed the importance of natural vegetation (Paredes et al., 2019) and extensive ground cover management (Paredes et al., 2015; Villa et al., 2016) for olive pest control. However, most studies in this agroecosystem have focused on arthropod natural enemies (Álvarez et al., 2019; Paredes et al. 2015), which seem to play an important role, with important economic implications (Paredes et al., 2019). Elucidating the significance of biocontrol by birds and how it is affected by landscape is especially necessary under the current scenario of progressive intensification that suffers this agroecosystem (Infante-Amate et al., 2016) and the remarked role of olive groves for the conservation of bird biodiversity in the Mediterranean region (Rey, 1993, 2011; Rey et al., 2019). In this study, we conduct field surveys together with two experiments involving plasticine dummies and bird exclosures at the regional scale. We experimentally investigate, for the first time, the predation potential of insectivorous birds on the two main olive tree pest species, the olive moth Prays oleae 
123 (Bernard,1788) and olive fly Bactrocera oleae (Rossi 1790), and the damages they

124 produce. We also test the effects of semi-natural patches attributes (e.g. patch size and

125 distance to the patch) and landscape compositional/configurational heterogeneity on:

126 insectivorous bird richness and abundance (with particular attention to forest insectivores),

127 pest abundance, attack rates on plasticine models, and observed crop damage. Our study is

128 conducted exclusively in organic olive farms to avoid potential confounding effects caused

129 by pesticides. Given the evidence of pest control by avian insectivores in other

130 agroecosystems, and provided the known sensibility of insectivorous birds to landscape

131 heterogeneity and presence of semi-natural habitat patches, we hypothesize that

132 insectivorous birds will exert effective pest control of major insect pests in olive orchards,

133 but their effectiveness would be strongly limited in homogeneous landscapes. Our

134 associated predictions are: (1) olive farms located in heterogeneous landscapes and non-

135 crop plots inside farms, will host a higher abundance/richness of insectivorous birds and

136 especially forest insectivores, as well as particular assemblages characterized by a higher

137 frequency of forest species; (2) bird-excluded branches will suffer more damage by pests

138 than controls (free access to birds) probing that birds are important for pest control, and

139 being this effect stronger in trees adjacent to semi-natural patches; (3) attack rates to pest

140 plasticine models, will be higher in heterogeneous landscapes, and close to semi-natural

141 patches. Alternatively, functional dilution of bird insectivory, due to the vast extent of olive

142 orchards in Andalusia, could be responsible for a limited pest control by birds in the olive-

143 dominated landscapes of the region. 


\subsection{Study area and study system}

147 Our study is set in Andalucía (south Spain), the region with the highest density of olive

148 trees worldwide. All surveys and experiments of this study were conducted in nine olive

149 farms that span $311 \mathrm{~km}$ distance from east to west (from $5 \square 53$ ' $46^{\prime \prime}$ 'W to $2 \square 64$ ' $87^{\prime \prime}$ 'W) and

$150190 \mathrm{~km}$ distance from north to south (from $38 \square 40^{\prime} 05^{\prime \prime} \mathrm{N}$ to $36 \square 78^{\prime} 36 \mathrm{~N}$ ). They are located

151 across a wide range of landscape complexity and were all organic, thereby not agricultural

152 management effect is here considered. For a map showing these localities and more details,

153 see Martínez $\square$ Núñez et al. (2019).

154 In this work we focus on two pest species: P. oleae (the olive moth) and B. oleae (the olive

155 fruit fly). The olive moth has a complex life cycle, completely adapted to the phenology of

156 the olive tree. This species has three generations. The phylophagous (leaf generation), a

157 small larva that feeds on olive tree leaves and builds galleries during winter-spring. The

158 anthophagous (flower generation), that feeds on floral buttons and flowers, matches the

159 flowering period of olive trees in Spring. The third one is the carpophagous larva (fruit

160 generation), the most harmful to production, causing premature fruit fall in Autumn

161 (Pelekassis, 1962). The olive fruit fly is an obligated pest of olive trees. The adult flies

162 oviposit their eggs in the fruit, where the larvae develop feeding on the fruit. The tunnels

163 produced by the larvae cause necrosis and possible fruit falling from the tree. In Autumn,

164 the larvae pupae in the olive fruit or in the soil, where they spend the winter (Daane \&

165 Johnson, 2010). 
168

169

170

171

172

173

174

175

176

177

178

179

180

181

182

183

184

185

186

187

188

189

190

We calculated several compositional and configurational variables of landscape

heterogeneity at the scale of $1 \mathrm{~km}$ radius from the centroid of each farm: SNA (amount of

total Semi-Natural Area, strongly correlated with Forest area; Pearson $\mathrm{r}=0.945, \mathrm{P}<0.001$ ),

ED (Edge Density), PD (patch diversity), PE (patch Evenness), OC (Amount of olive

cover), PR (Patch Richness), LPS (Largest patch size), PA (mean Patch Area), NND

(Distance to Nearest Neighbor patch of same type) and SDI (Shape Distribution Index).

They were computed using the most recent and accurate land-use cartography of the region

(SIOSE, http://www.siose.es), QGIS v.2.14 (QGIS Development Team, 2018) and

FRAGSTATS software (McGarigal et al., 2012). Because some of them were highly

correlated (see correlogram; Figure A.1, in Appendix A), we eventually selected 6

landscape variables that are the most commonly used and represented very well all the information: SNA, ED, PD, OC, PR, and NND.

\subsection{Bird surveys}

Birds were surveyed monthly from March 2016 to April 2017 (except July and August, 10

rounds) in six or ten permanent plots per farm (depending on farm size) separated by ca.

200m. Inside each farm, two (in small farms) or four (in big farms) of the plots were sited

in patches of semi-natural habitat (non-crop plots hereafter), and the rest of the plots were

inside the matrix of the olive plantation (crop plots hereafter). This, allowed to sample

communities at the farm scale, capturing farm heterogeneity, and also enabled comparisons

between plot types (habitat or microhabitat effects). In these plots, experienced

ornithologists annotated the birds listened or seen for five minutes, within and outside a

circle of 50m radius from the center of the plot. Censuses were conducted within three 
191 hours after sunrise. For this study, only insectivorous birds were accounted. Species were

192 classified as insectivorous based on expert knowledge, and validated using the functional

193 trait database by Storchová \& Hořák (2018) and Wilman et al., (2014). Because forest birds

194 might have a greater impact on pests (they forage more specifically on trees, where pests

195 might be more vulnerable to birds), this same database was also used to classify birds as

196 forest or open habitat species.

\subsection{Pest abundance}

199 We monitored the abundance of olive moth, by using funnel traps with pheromone z-7-

200 tetradecen-1-ol that attracts adult males and an insecticide pill. Monitoring was conducted

201 from April to July 2017, with monthly rounds to count trapped moths. We also monitored

202 the abundance of adult olive flies in the 9 organic olive farms, from July to November

203 2016. For that, we set McPhail traps with the attractant ammonium bisulfate ((NH4) HSO4)

204 diluted in water (4\%). In every olive farm, we set a total of 6 (in small farms, < 25 ha) or 10

205 (in big farms, >100 ha) traps, hanging from olive trees widespread throughout the whole

206 farm. McPhail traps were monthly checked and refilled with liquid.

\subsection{Bird exclusion experiment}

209 In this study, we measured the potential of insectivorous birds to control olive tree pests.

210 We designed an experiment to preclude birds from accessing some branches. The damages

211 observed in excluded branches were compared with those detected in control branches

212 (parallel, close and similar to the experimental branch) that were not excluded from birds 
213 (e.g., Maas, Clough, \& Tscharntke, 2013 for a similar approach). The aim of this

214 experiment was to test the possible top-down effect of birds on olive tree damage, through

215 arthropod/pest control. In each farm, 10 trees were selected, 5 non-consecutive trees in the

216 first row adjacent to a patch of semi-natural habitat and 5 within the olive tree matrix (far

217 from a patch of semi-natural habitat), ca. 100-120m away from the reference semi-natural

218 patch. Bird mist-netting data from these two orchard positions clearly show that

219 insectivorous bird activity is notably higher in the non-crop patches (authors' unpublished

220 data). Each selected tree had 4 excluded branches, and its corresponding control branches

221 nearby. To exclude branches from birds, we used a cylinder of $80 \mathrm{~cm}$ long and $25 \mathrm{~cm}$

222 diameter made by $1 \mathrm{~cm}^{2}$ pore plastic mesh. The ends were closed using $2 \mathrm{~mm}^{2}$ pore plastic

223 mesh (Figure A.2, in Appendix A). In total, we set 360 exclusions in 90 trees at the very

224 beginning of March and were kept throughout the year. We conducted three check rounds,

225 measuring four types of damages to leaves, flowers and fruits. Specifically, we sampled: i)

226 leaf damage produced by leaf miner larvae of the olive moth and other phytophagous

227 insects at the end of March; ii) leaf and flower damage by anthophagous larvae of the olive

228 moth and other phyllophagous insects at the end of May; iii) leaf and fruit damage, by the

229 moth, the fly and other phyllophagous insects at the end of October-beginning of

230 November.

231

$232 \quad 2.6$ Artificial prey experiment

233 We employed plasticine models to compare the potential of avian predation pressure on

234 two olive pest species across our landscape complexity gradient. This is a methodology

235 commonly used in field experiments to assess and compare attack rates by specific predator 
236 guilds towards specific preys (Howe, Lövei, \& Nachman, 2009; Lövei \& Ferrante, 2017).

237 We mimicked larvae of two generations of olive moth (phyllophagous generation in March-

238 April and anthophagous generation in May) and the larval stage of olive fly (in October-

239 December), being all the stages considered as temporal replicates of the same treatment. In

240 each round, we set 4 plasticine models per tree, in 5 trees near a patch of semi-natural

241 vegetation and 5 trees inside the olive orchard matrix. Selected olive trees were separated

242 from others by at least another tree, ca. 20-30 m. Dummies were fixed to the ground, leaves

243 or flowers depending on the pest and generation we tried to mimic (Figure A.2 in Appendix

244 A). We conducted a total of 6 rounds per site (2 rounds per pest and larval stage), and a

245 total of 2160 plasticine models were used (240 per site). We detected and counted predation

246 marks by birds (beak mark) and by other predators (mainly ants, many small bites) on the

247 plasticine models. All dummies were checked after $7 \pm 1$ day of exposure (Mäntylä et al.,

248 2008) (with the exception of the first round where we tried 15 days \pm 2 days). This method

249 has been criticized in some systems for being not realistic (Zou et al., 2017), therefore we

250 firstly set trap cameras to successfully validate some predation events by birds on our

251 plasticine models.

\section{$253 \quad 2.7$ Statistical analyses}

254 First, we sought for patterns linking the abundance and richness of insectivorous birds to

255 landscape complexity. Because some vulnerable stages of the studied pests are found on the

256 ground, we first accounted for overall insectivorous birds. However, we reran the analyses

257 accounting only for forest insectivorous birds, since this guild might have a greater impact

258 on olive pests (they can forage on trees). For that, we ran Bayesian models with 
insectivorous bird abundance/bird richness as response variables and the six landscape

260 components (see above, e.g. amount of semi-natural area, edge density, etc) at the scale of 1

$261 \mathrm{~km}$ radius, as explanatory variables. Farm ID entered the models as a random factor.

262 Response variables were log transformed to run normal models. We employed multilevel 263 mixed Bayesian models fitted through the MCMC (Markov Chain Monte Carlo) method

264 using the brms package (Bürkner, 2017) in $R$ (R Core Team 2019). Results were interpreted 265 as the posterior probability of beta (slope) being positive/negative. This kind of model

266 enables us to run hierarchical mixed models. Also, Bayesian models are more easy and

267 straightforward to interpret, especially for designs with a small-moderate number of cases,

268 allow probabilistic predictions, and inferences are conditional on the data (which means

269 that are exact). We also analyzed bird abundance/richness variation (for insectivorous birds

270 and forest insectivorous birds) between plot types (non-crop plots and crop plots) within

271 each farm. For this, we fitted Bayesian models, with bird abundance/richness as response

272 variable and plot type as explanatory factor. Farm ID was also introduced as blocking

273 random factor. We also explored differences in species assemblages, by analyzing how

274 species-specific probability of occurrence varied across our range of landscape

275 heterogeneity measured at $1 \mathrm{~km}$ radius, using Hierarchical Modelling of Species

276 Communities (HMSC) (Ovaskainen et al., 2017). A detailed description of methodology,

277 results and discussion of species assemblages' variation is shown in Appendix B.

278 Second, we tested how pest abundance varied with landscape heterogeneity and bird

279 abundance/richness (for overall insectivores and forest insectivores, separately), using

280 Bayesian mixed models. We ran one model for each explanatory variable (six landscape

281 components, bird abundance and bird richness) and each response variable (pest species; 
282 olive moth and olive fly). Farm ID was introduced as a random factor and the six landscape variables and bird abundance/richness as fixed factors. We inferred the results by testing the hypothesis of the posterior beta parameter being higher or lower than 0 .

Third, we ran the same type of multilevel Bayesian mixed models, using the brms package to look for patterns in the damage observed in excluded and control branches. The response variable, damage, was arcsine square root transformed since it was a proportion (observed damage in relation to number of leaves, flowers and fruits counted). The explanatory variables were treatment (excluded vs. control) and site (close to a semi-natural patch or in the olive tree matrix, away from the semi-natural patch). Farm and tree ID were introduced as random factors. Additionally, we explored interactive effects of landscape complexity and distance to semi-natural patch on observed damage, because we expected less effect of distance in complex landscapes. These interactions did not explain variance in observed damage and were removed from models.

Finally, we tested how observed attack rates in pest dummies varied in relation to landscape components, bird abundance, bird richness, size of focal semi-natural patch and distance to semi-natural patch (as factor: close-distant). Attack rates (attacked/exposed) were arcsine square root transformed and linear mixed Bayesian models fitted. Farm ID was included as random factor in every model.

For all the Bayesian models, we checked convergence through $\mathrm{R}^{\wedge}$ (all equal to 1 or 1.01 ), normality of the residuals and stability of results (by visual inspection of chains). We also inspected models' goodness of fit via plots confronting observed data with posterior data generated using model simulations ( $\mathrm{N}=200$ datasets simulated). For all models, we used 
uninformative diffuse priors and model specifications that rendered stable outputs (4 chains

305 and 50000 iterations with the first 10000 being burned).

306 All the analyses were run using $R$, version 3.6.1 (R Core Team 2019).

\section{Results}

During surveys, 86 different species of insectivorous birds, belonging to 62 genera and 36

families were identified; 47 of them were forest insectivores, from 36 different genera (see

Table A.1 in Appendix A for the complete list of species). A number of 4966 insectivorous

312 birds was detected across the year inside the 50m radius plots, of which 3349 were forest

313 insectivores. The most abundant species were the sardinian warbler (Sylvia melanocephala;

$31415.9 \%$ of the total), the eurasian blackcap (Sylvia atricapilla; 11.8\%), the common chaffin

315 (Fringilla coelebs; 10.9\%) and the european robin (Erithacus rubecula; 10.5\%). Among

316 bird families typically considered important for pest control in tree crops, both Paridae (4

317 species and $11 \%$ of total abundance) and Picidae ( 3 species and $0.2 \%$ of total abundance)

318 were scarce in olive orchards. Thus, Parus major was the most frequent (8\%) followed by

319 Cyanistes caeruleus (3\%) while Lophophanes cristatus and Periparus ater were rather rare

320 and, as Picus viridis, Dendrocopos major and Jynx torquilla, appeared only associated to

321 semi-natural and riparian forest patches.

322 The abundance of insectivorous birds did not vary importantly between olive farms

323 surrounded by landscapes of different complexity (see Table 1). Only edge density

324 increased the abundance of birds (Mean beta estimated $=0.14$; Prob $\beta>0=0.94$ ).

325 However, species richness increased considerably in plots with landscapes showing a 
326 higher patch diversity (Mean beta estimated $=0.29$; Prob $\beta>0=0.96$ ). Accordingly,

327 landscapes dominated by olive orchards (Mean beta estimated $=-0.06 ;$ Prob $\beta<0=0.91$ )

328 and with low distance to nearest similar patch decreased bird richness (Mean beta estimated

$329=-0.11 ;$ Prob $\beta<0=0.99$ for). These results were reinforced for forest insectivores. Their

330 abundance increased in plots within landscapes with high density of edges (Mean beta

331 estimated $=0.15$; Prob $\beta>0=0.98)$ and their species richness increased in those with more

332 semi-natural area (Mean beta estimated $=0.07$; Prob $\beta>0=0.91$ ) and edge density (Mean

333 beta estimated $=0.12$; Prob $\beta>0=0.98$ ). Within farms, insectivorous birds were also

334 strongly associated to non-crop patches (Table A.2, in Appendix A), showing lower

335 abundance in crop patches (Mean beta estimated $=-0.31$; Prob $\beta>0=0$ ). This pattern was

336 stronger when only forest insectivores were considered, decreasing their abundance (Mean

337 beta estimated $=-0.40 ;$ Prob $\beta>0=0)$ and species richness (Mean beta estimated $=-0.09$;

338 Prob $\beta>0=0.05$ ) in crop plots. Additionally, we detected clear patterns of insectivorous

339 bird species turnover as a function of landscape heterogeneity (see Appendix B).

340 The abundance of pests captured with traps was notable in all olive orchards (ranging from

$341277 \pm 127$ to $2216 \pm 205$ for the moth; and $21 \pm 17$ to $625 \pm 228$ mean captures/trap \pm 1 SD for

342 the fly). The abundance of the moth was correlated negatively with SNA, ED and PD

343 (Posterior beta $<0$ with a probability of 1) but the abundance of the fly did not show any

344 remarkable pattern. Also, neither the moth nor the fly abundance were related to total

345 insectivorous or forest insectivorous bird abundance or richness (see Table A.3 in

346 Appendix A).

347 There were no differences between the control and excluded branches (see Table 2 and Fig.

348 1) regarding damage caused by the moth (Mean beta excluded branch $=-0.01$, Prob $\beta>0=$ 
349 0.25). However, excluded branches showed less damage for the fly (Mean beta excluded

350 branch $=-0.10$, Prob $\beta>0=0$ ), phyllophagous insects (Mean beta excluded branch $=-0.05$,

351 Prob $\beta>0=0$ ) and overall pests (Mean beta excluded branch $=-0.04$, Prob $\beta>0=0$ ).

352 Trees adjacent to semi-natural patches suffered less damage than trees sited in the olive

353 matrix for all the type of damages measured (Mean beta for matrix trees $=0.04$, Prob $\beta>0$

$354=1$ for the moth; 0.05 , Prob $\beta>0=0.98$ for the fly; 0.06 , Prob $\beta>0=1$ for phyllophagous

355 insects; and 0.05, Prob $\beta>0=1$ for cumulated damage) (Table 2 and Fig. 1).

356 The observed attack rates in plasticine models were extremely low, $\mathrm{N}=144$ bird attacks

357 (less than $0.8 \% \mathrm{~d}^{-1}$ ) and $\mathrm{N}=344$ total attacks (by birds plus others, slightly over $1.9 \% \mathrm{~d}^{-1}$ )

358 (Fig. 2). There were no meaningful patterns explained either by landscape characteristics or

359 distance to semi-natural patches, which probably means that the low attack rates were

360 insufficient to show reliable patterns across landscapes or distance to seminatural patches.

\section{Discussion}

The results obtained supported our first prediction, since heterogeneous landscapes and

364 non-crop habitats tended to host a higher abundance, richness, and a particular assemblage

365 of insectivorous birds (particularly benefitting forest insectivores). However, excluded

366 branches did not suffer more damage by pests, and attack rates to plasticine models were

367 too scarce to show reliable patterns across landscapes and farms. Therefore, none of our

368 two last predictions were supported by the results, suggesting that the pest control

369 ecosystem service provided by insectivorous birds in olive orchards might be in a worrying

370 situation. 


\subsection{Landscape effects on insectivorous birds}

373 Despite the relatively low number of olive orchards considered, we did find a positive trend

374 in insectivorous bird abundance and richness driven by some components of landscape

375 heterogeneity. Interestingly, such differences were stronger for abundance and richness of

376 forest insectivores. Consistently with other studies (e.g. García, Miñarro \& Martínez-Sastre,

377 2018; Karp et al., 2013), more species of forest insectivores were found in landscapes with

378 a higher proportion of semi-natural habitats. Results also showed important differences at

379 the farm scale, with non-crop plots supporting a more abundant and rich community of

380 insectivores (particularly forest insectivores) than crop plots. The underlying reason for

381 these findings might be that complex landscapes offer more variability of niches, resources

382 and higher food availability, being able to support a wider community of these

383 insectivorous birds. This is further supported by our finding of important species turnover

384 across our landscape gradients (Appendix B).

387 The experiment with bird exclusions supported the lack of effective pest control by current populations of insectivorous birds in olive orchards. While other studies conducted in

389 orchards and agroforests have found more damage in branches/trees excluded to birds

390 (García, Miñarro \& Martínez-Sastre, 2018; Maas, Clough, \& Tscharntke, 2013), we found 391 similar or lower damage in excluded branches compared to control branches across all our 392 study sites. For the fly and other phyllophagous insects, we found more damage in control 
branches. These results might be due to intraguild predation, with birds predating on other

394 insect predators such as ants or spiders in control branches, and thus releasing pests from

395 these mesopredators (Maas et a. 2016). In any case, birds did not reduce pest damage.

396 Interestingly, trees close to semi-natural patches showed less damage than trees located

397 inside the olive tree matrix. This decrease in damage was not affected by branch treatment

398 (excluded or control), which suggests that some small arthropods associated to semi-natural

399 patches are effective natural enemies against these two olive pests. Their predation pressure

400 might influence pest preference for inner trees or directly reduce pest populations in trees

401 close to semi-natural patches. Some studies have pointed out the key role of arthropod

402 natural enemies such as Anthocoris nemoralis (Fabricius) (Paredes et al., 2019) or other

403 ground arthropods (Dinis et al., 2016) in olive orchards. Semi-natural patches and ground

404 cover seem to have a vital function, providing habitat and alternative prey for them

405 (Álvarez et al., 2019; Paredes et al., 2019). This result endorses the positive effect of

406 natural fragments on pest control in agroecosystems, and the higher predation observed in

407 areas close to semi-natural patches/ecotones, already reported by other authors in different

408 systems (Barbaro, Giffard, Charbonnier, van Halder, \& Brockerhoff, 2014; Maas et al.,

409 2015; Milligan, Johnson, Garfinkel, Smith, \& Njoroge, 2016).

410 The recorded attack rates to plasticine models did not follow any pattern associated to

411 landscape features. The results obtained in this experiment agree with the previous

412 experiment (i.e. branch exclusions) because attack rates by birds were extremely low.

413 Despite that recorded predation is usually higher on real preys than on dummy (Lövei \&

414 Ferrante, 2017), observed numbers are well under attack rates needed for an effective pest

415 control. Higher attack rates on dummy preys have been found in other agricultural systems 
416

417

418

419

420

421

422

423

424

425

426

427

428

429

430

431

432

433

434

435

436

437

438

such as: oil palm plantations (37\% without and 53\% with riparian forest fragments) (Gray \& Lewis, 2014), apple plantations (63\%, Martínez-Sastre et al. in press), cacao agroforest $\left(2.9 \% \mathrm{~d}^{-1}\right.$ attack rate by birds, and $6.5 \% \mathrm{~d}^{-1}$ including all arthropods) (Maas et al., 2015) or cotton fields (ca. 4\% d d $^{-1}$ ) (A. G. Howe, Nachman, \& Lövei, 2015). As noted by Lövei \& Ferrante (2017), relative low densities of natural preys can increase attack rates to dummy preys. Some authors have shown this effect by detecting increased attack rates in more disturbed areas (rural areas vs. open and closed canopy forests) (Posa, Sodhi, \& Koh, 2007). Large numbers of these pests, added to a relatively low abundance of insectivorous birds using olive orchards could explain the negligible attack rates found in our study (see next section). Some authors have found a correlation between attack rates (to plasticine models) and the abundance of insectivorous birds surveyed with mist-nets (Maas et al., 2015). This method might be better than conventional surveys to address the birds that are really entering in the olive tree matrix, in contrast to birds that use the semi-natural patches but are rarely found inside the olive orchards.

\subsection{Functional dilution hypothesis}

We recorded a high number of adult pests with traps (mean of 1372/trap for olive moth, and 134/trap for olive fly), and the observed damage was high as well (ca. 15\% damaged by

olive moth; ca. $30 \%$ by olive fly; and ca. $60 \%$ of leaves damaged by phyllophagous insects), evidencing a high density of the moth, the fly, and phyllophagous insects in the studied farms. However, despite this temporal high availability of prey, insectivorous birds seem to make a limited use of olive orchards and crop plots inside farms, as to be effective controlling these pests. This overall limited use of olive orchards would indicate low 
attractiveness of the olive matrix for avian insectivore guilds, especially forest insectivores. This is supported by the fact that insectivorous bird assemblages clearly augmented in noncrop patches within farm compared to the crop matrix, this being even more marked for forest insectivores. Some other studies have also shown that the richness and abundance of insectivorous-frugivorous birds decline (at least in autumn-winter) in olive groves compared to semi-natural wild olive scrublands and other reference woodlands (Alcántara et al., 1997a; Rey, 1993). These declines in avian insectivore may suppose well above one order of magnitude in terms of energetic requirement by hectare of the whole insectivore guild between these habitats (Alcántara et al. 1997b). Forest insectivores have also been shown to decline in olive orchards during the reproductive season as a function of agriculture intensification and/or landscape simplification (Castro-Caro, Barrio, \& Tortosa, 2015; Morgado et al. 2020). Such limited attractiveness of the olive tree matrix may be related with the current suboptimal (structural and feeding) conditions of this habitat where the management originates regular distribution of trees, absence of nesting cavities on tree trunks, short and reduced tree canopies, and lack of permanent scrub and/or herbaceous layers and their associated food resources.

On the other hand, the observed mismatch between prey-predator abundance might be partially caused by relatively scarce and small semi-natural areas at the olive farm and landscape scales. Thus, there are little resources (e.g. alternative preys or nesting sites) to host a bird community large enough to exert an important insectivory pressure. Moreover, the ratio natural to crop area needed in Mediterranean agroecosystems to effectively sustain insectivorous bird populations should be higher than this ratio in other places (e.g. tropical areas), because semi-natural patches have typically low productivity in Mediterranean 
462

463

464

465

466

467

468

469

470

471

472

473 474 decline.

475

476

477

478

479

480

481

482

483

484 environments (as a consequence of the severe summer drought) compared to tropical and non-Mediterranean temperate ones (Imhoff \& Bounoua, 2006). This likely prevents the permanent presence of large enough populations and rich assemblages of insectivorous birds within olive orchards.

Therefore, it is likely that avian insectivore density in the tree matrix of olive farms at any landscape was under the threshold levels needed for an effective pest control. We argue, thus, for a functional dilution hypothesis to explain the non-effective pest control by birds in olive orchards. This hypothesis states that avian predation pressure and control over pests is diluted at the landscape level due to low numbers of predators and natural habitat, compared to the abundance of pests and the extent of crop area. Similar findings were reported by McConkey \& Drake (2006), where the authors detected the loss of an ecosystem service (seed dispersal) provided by bats, well before important bat population

To our knowledge, this is the first study to assess pest control by birds in olive orchards, which hinders further comparison of our results. However, Rey Benayas et al., (2017) set an experiment in several Mediterranean woody crops, including olive orchards, using bird nest boxes and alive sentinel preys. The nest boxes set in olive orchards were not occupied throughout the four-year study, and therefore, no attack rates were available for this system. Lack of occupation of nest boxes in this system is congruent with our results reporting a worrying situation for insectivorous birds and their contribution to pest control in olive orchards. Nonetheless, we cannot discard that our results on pest control by birds might be reflecting a relatively low bird appetence for the two pest species studied (Tscharntke et al., 2016). Unfortunately, there is a notable gap in studies analyzing bird insectivore diet in 
485 olive groves in relation to its major pests, whereby there is no information of reference. As

486 done in other agroecosystems (e.g., Karp et al. 2013 in coffee plantations or Mangan et al.

4872018 in apple orchards), studies analyzing bird diet with molecular tools (e.g. DNA

488 analyses form faecal sampling) are needed to elucidate how frequently insectivorous birds

489 feed on olive pests.

\section{Conclusion}

492 This study suggests that insectivorous birds are unable to provide an effective biological

493 control service for the two main olive tree pests in Andalusia (Spain). Our results might

494 be showing the serious consequences of current low insectivorous bird densities on the

495 pest control ecosystem service carried out in olive orchards. Since alarming bird declines

496 have been reported in North America (Rosenberg et al., 2019) and Europe in the last

497 decades (Bowler, Heldbjerg, Fox, de Jong, \& Böhning-Gaese, 2019; Inger et al., 2015),

498 avian insectivory function in olive orchards is expected to be aggravated in the olive

499 farms in the near future, since olive matrix is clearly suboptimal for avian insectivores,

500 and suboptimal habitats become empty earlier that optimal ones. According to our results,

501 urgent actions should be taken to reverse this situation, such as policy changes aimed to

502 the recuperation of landscape heterogeneity and semi-natural patches in landscapes

503 homogenized by monoculture, and active restoration of bird assemblages (e.g. setting bird

504 nest boxes and feeders). 


\section{Author's contributions}

508

509

510

511

512

513

\section{Acknowledgements}

515 We thank the farmers who collaborated with us, granting access to their properties. We also

516 thank Antonio J. Pérez, Gemma Calvo, Maria José Navarro, Francisco Camacho, Enrique

517 Muñoz and Sandra Lendínez for helping with fieldwork. Finally, we thank Francisco

518 Valera, José E. Gutiérrez and Carlos Ruiz for logistic support. This work is part of the

519 projects AGRABIES (CGL2015 $\square 68963 \square$ C2, MINECO, Gobierno de España and FEDER)

520 and LIFE OLIVARES VIVOS (LIFE14 NAT/ES/001094, European Commission). CMN

521 was granted a predoctoral fellowship (BES-2016-078736). Authors have no conflict of

522 interest.

\section{Data deposition information}

524 Should the manuscript be accepted, data will be uploaded to the Mendeley Data repository.

\section{Ethics declarations}

526 Conflict of interest:

527 The authors declare they have no conflict of interest. 
528

529

530

Informed consent:

Informed consent was obtained from all individual participants included in the study.

\section{References}

Alcántara, J. M., Rey, P. J., Valera, F., Sánchez-Lafuente, A. M., Gutiérrez, J. E. (1997a). Habitat Alteration and Plant Intra-Specific Competition for Seed Dispersers. An Example with Olea europaea var. sylvestris. Oikos, 79(2), 291. https://doi.org/10.2307/3546013

Alcántara, J.M., Rey, P.J., Valera, F., Gutiérrez, J.E. y Sánchez-Lafuente, A.M. (1997b). Temporal pattern of seed dispersal of wild olive (Olea europaea var. Sylvestris): Its effect on intra-specific competition. Lagascalia, 19 (1-2), 583-590.

Álvarez, H. A., Morente, M., Oi, F. S., Rodríguez, E., Campos, M., \& Ruano, F. (2019). Semi-natural habitat complexity affects abundance and movement of natural enemies in organic olive orchards. Agriculture, Ecosystems \& Environment, 285, 106618. https://doi.org/10.1016/J.AGEE.2019.106618

Bael, S. A. Van, Philpott, S. M., Greenberg, R., Bichier, P., Barber, N. A., Mooney, K. A., \& Gruner, D. S. (2008). Birds as predators in tropical agroforestry systems. Ecology, 89(4), 928-934. https://doi.org/10.1890/06-1976.1

Barbaro, L., Giffard, B., Charbonnier, Y., van Halder, I., \& Brockerhoff, E. G. (2014). Bird functional diversity enhances insectivory at forest edges: a transcontinental experiment. Diversity and Distributions, 20(2), 149-159. https://doi.org/10.1111/ddi.12132 
Barbaro, L., Rusch, A., Muiruri, E. W., Gravellier, B., Thiery, D., \& Castagneyrol, B. (2017). Avian pest control in vineyards is driven by interactions between bird functional diversity and landscape heterogeneity. Journal of Applied Ecology, 54(2), 500-508. https://doi.org/10.1111/1365-2664.12740

Bateman, P. W., Fleming, P. A., \& Wolfe, A. K. (2017). A different kind of ecological modelling: the use of clay model organisms to explore predator-prey interactions in vertebrates. Journal of Zoology, 301(4), 251-262. https://doi.org/10.1111/jzo.12415

Bereczki, K., Ódor, P., Csóka, G., Mag, Z., \& Báldi, A. (2014). Effects of forest heterogeneity on the efficiency of caterpillar control service provided by birds in temperate oak forests. Forest Ecology and Management, 327, 96-105. https://doi.org/10.1016/J.FORECO.2014.05.001

Boesing, A. L., Nichols, E., \& Metzger, J. P. (2017). Effects of landscape structure on avian-mediated insect pest control services: a review. Landscape Ecology, 32(5), 931944. https://doi.org/10.1007/s10980-017-0503-1

Bowler, D. E., Heldbjerg, H., Fox, A. D., de Jong, M., \& Böhning-Gaese, K. (2019). Longterm declines of European insectivorous bird populations and potential causes. Conservation Biology. https://doi.org/10.1111/cobi.13307

Bürkner, P.-C. (2017). brms $\square$ : An $R$ Package for Bayesian Multilevel Models Using Stan. Journal of Statistical Software, 80(1), 1-28. https://doi.org/10.18637/jss.v080.i01

Castro-Caro, J. C., Barrio, I. C., \& Tortosa, F. S. (2015). Effects of Hedges and Herbaceous Cover on Passerine Communities in Mediterranean Olive Groves. Acta Ornithologica, 50(2), 180-192. https://doi.org/10.3161/00016454AO2015.50.2.006 
571 Daane, K. M., \& Johnson, M. W. (2010). Olive Fruit Fly: Managing an Ancient Pest in

572 Modern Times. Annual Review of Entomology, 55(1), 151-169.

573 https://doi.org/10.1146/annurev.ento.54.110807.090553

Dinis, A. M., Pereira, J. A., Pimenta, M. C., Oliveira, J., Benhadi-Marín, J., \& Santos, S. A. arthropods in the olive grove. Journal of Applied Entomology, 140(9), 677-687. https://doi.org/10.1111/jen.12291

578

579

Escobar-Ramírez, S., Grass, I., Armbrecht, I., \& Tscharntke, T. (2019). Biological control of the coffee berry borer: Main natural enemies, control success, and landscape influence. Biological Control, 136, 103992. https://doi.org/10.1016/J.BIOCONTROL.2019.05.011

García, D., Miñarro, M., \& Martínez-Sastre, R. (2018). Birds as suppliers of pest control in cider apple orchards: bird biodiversity filters and insectivore effect. Agriculture, Ecosystems \& Environment, 254(November 2017), 233-243. https://doi.org/https://doi.org/10.1016/j.agee.2017.11.034

Gonthier, D. J., Sciligo, A. R., Karp, D. S., Lu, A., Garcia, K., Juarez, G., ... Kremen, C. (2019). Bird services and disservices to strawberry farming in Californian agricultural landscapes. Journal of Applied Ecology, 1365-2664.13422. https://doi.org/10.1111/1365-2664.13422

Grab, H., Danforth, B., Poveda, K., \& Loeb, G. (2018). Landscape simplification reduces classical biological control and crop yield. Ecological Applications, 28(2), 348-355. https://doi.org/10.1002/eap.1651 
593 Gray, C. L., \& Lewis, O. T. (2014). Do riparian forest fragments provide ecosystem

$594 \quad$ services or disservices in surrounding oil palm plantations? Basic and Applied

595

Ecology, 15(8), 693-700. https://doi.org/10.1016/J.BAAE.2014.09.009

596

597

598

599

600

601

602

603

604

605

606

607

608

609

610

611

612

613

614

HE, H. ming, LIU, L. na, Munir, S., Bashir, N. H., WANG, Y., YANG, J., \& LI, C. yun. (2019, September 1). Crop diversity and pest management in sustainable agriculture. Journal of Integrative Agriculture. Chinese Academy of Agricultural Sciences. https://doi.org/10.1016/S2095-3119(19)62689-4

Henri, D. C., Jones, O., Tsiattalos, A., Thébault, E., Seymour, C. L., \& van Veen, F. J. F. (2015). Natural vegetation benefits synergistic control of the three main insect and pathogen pests of a fruit crop in southern Africa. Journal of Applied Ecology, 52(4), 1092-1101. https://doi.org/10.1111/1365-2664.12465

Howe, A. G., Nachman, G., \& Lövei, G. L. (2015). Predation pressure in Ugandan cotton fields measured by a sentinel prey method. Entomologia Experimentalis et Applicata, 154(2), 161-170. https://doi.org/10.1111/eea.12267

Howe, A., Lövei, G. L., \& Nachman, G. (2009). Dummy caterpillars as a simple method to assess predation rates on invertebrates in a tropical agroecosystem. Entomologia Experimentalis et Applicata, 131(3), 325-329. https://doi.org/10.1111/j.15707458.2009.00860.x

Imhoff, M. L., \& Bounoua, L. (2006). Exploring global patterns of net primary production carbon supply and demand using satellite observations and statistical data. Journal of Geophysical Research, 111(D22), D22S12. https://doi.org/10.1029/2006JD007377

Infante-Amate, J., Villa, I., Aguilera, E., Torremocha, E., Guzmán, G., Cid, A., \& González 
de Molina, M. (2016). The Making of Olive Landscapes in the South of Spain. A History of Continuous Expansion and Intensification (pp. 157-179). Springer, Cham. https://doi.org/10.1007/978-3-319-26315-1_8

Inger, R., Gregory, R., Duffy, J. P., Stott, I., Voříšek, P., \& Gaston, K. J. (2015). Common European birds are declining rapidly while less abundant species' numbers are rising. Ecology Letters, 18(1), 28-36. https://doi.org/10.1111/ele.12387

Jordani, M. X., Hasui, É., \& da Silva, V. X. (2015). Natural enemies depend on remnant habitat size in agricultural landscapes. Journal of Forestry Research, 26(2), 469-477. https://doi.org/10.1007/s11676-015-0043-y

Karp, D. S., Mendenhall, C. D., Sandí, R. F., Chaumont, N., Ehrlich, P. R., Hadly, E. A., \& Daily, G. C. (2013). Forest bolsters bird abundance, pest control and coffee yield. Ecology Letters, 16(11), 1339-1347. https://doi.org/10.1111/ele.12173

Koh, L. P. (2008). Birds defend oil palms from herbivorous insects. Ecological Applications, 18(4), 821-825. https://doi.org/10.1890/07-1650.1

Lewis, W., Lenteren, J. van, Phatak, S., \& Tumlinson, J. (2013). A total system approach to sustainable pest management. PNAS, 94(23), 12243-12248. https://doi.org/10.1073/pnas.94.23.12243

Linden, V. M. G., Grass, I., Joubert, E., Tscharntke, T., Weier, S. M., \& Taylor, P. J. (2019). Ecosystem services and disservices by birds, bats and monkeys change with macadamia landscape heterogeneity. Journal of Applied Ecology, 56(8), 13652664.13424. https://doi.org/10.1111/1365-2664.13424

Lövei, G. L., \& Ferrante, M. (2017). A review of the sentinel prey method as a way of 
quantifying invertebrate predation under field conditions. Insect Science, 24(4), 528542. https://doi.org/10.1111/1744-7917.12405

Maas, B., Clough, Y., \& Tscharntke, T. (2013). Bats and birds increase crop yield in tropical agroforestry landscapes. Ecology Letters, 16(12), 1480-1487. https://doi.org/10.1111/ele.12194

Maas, B., Tscharntke, T., Saleh, S., Dwi Putra, D., \& Clough, Y. (2015). Avian species identity drives predation success in tropical cacao agroforestry. Journal of Applied Ecology, 52(3), 735-743. https://doi.org/10.1111/1365-2664.12409

Maas, B., Karp, D. S., Bumrungsri, S., Darras, K., Gonthier, D., Huang, J. C. C., ... Williams-Guillén, K. (2016). Bird and bat predation services in tropical forests and agroforestry landscapes. Biological Reviews, 91(4), 1081-1101. https://doi.org/10.1111/brv.12211

Mangan, A. M., Piaggio, A. J., Hopken, M. W., Werner, S. J., \& Pejchar, L. (2018). A molecular analysis to assess codling moth Cydia pomonella L. (Lepidoptera: Tortricidae) predation by orchard birds. Ecological Indicators, 93, 1222-1225. https://doi.org/10.1016/j.ecolind.2018.06.025

Mäntylä, E., Alessio, G. A., Blande, J. D., Heijari, J., Holopainen, J. K., Laaksonen, T., ... Klemola, T. (2008). From Plants to Birds: Higher Avian Predation Rates in Trees Responding to Insect Herbivory. PLoS ONE, 3(7), e2832. https://doi.org/10.1371/journal.pone.0002832

Martínez $\square$ Núñez, C., Manzaneda, A. J., Lendínez, S., Pérez, A. J., Ruiz $\square$ Valenzuela, L., \& Rey, P. J. (2019). Interacting effects of landscape and management on plant $\square$ solitary 
659

660

661

662

663

664

665

666

667

668

669

670

671

672

673

674

675

676

677

678

679

680

bee networks in olive orchards. Functional Ecology, 1365-2435.13465.

https://doi.org/10.1111/1365-2435.13465

Martínez-Sastre R., Miñarro M., \& García D. Animal biodiversity in cider apple orchards: simultaneous environmental drivers and effects on insectivory and pollination. Agriculture, Ecosystems \& Environment. In press.

McConkey, K. R., \& Drake, D. R. (2006). Flying foxes cease to function as seed dispersers long before they become rare. Ecology, 87(2), 271-276. https://doi.org/10.1890/050386

McGarigal, K., SA Cushman, and E Ene. 2012. FRAGSTATS v4: Spatial Pattern Analysis Program for Categorical and Continuous Maps. University of Massachusetts, Amherst.

Milligan, M. C., Johnson, M. D., Garfinkel, M., Smith, C. J., \& Njoroge, P. (2016). Quantifying pest control services by birds and ants in Kenyan coffee farms. Biological Conservation, 194, 58-65. https://doi.org/10.1016/J.BIOCON.2015.11.028

Mols, C. M. M., \& Visser, M. E. (2007). Great tits (Parus major) reduce caterpillar damage in commercial apple orchards. PLoS ONE, 2(2). https://doi.org/10.1371/journal.pone.0000202

Morgado, R., Santana, J., Porto, M., Sánchez-Oliver, J. S., Reino, L., Herrera, J. M., ... Moreira, F. (2020). A Mediterranean silent spring? The effects of olive farming intensification on breeding bird communities. Agriculture, Ecosystems \& Environment, 288, 106694. https://doi.org/10.1016/j.agee.2019.106694

Ovaskainen, O., Tikhonov, G., Norberg, A., Guillaume Blanchet, F., Duan, L., Dunson, D., ... Abrego, N. (2017). How to make more out of community data? A conceptual 
681

682

683

684

685

686

687

688

689

690

691

692

693

694

695

696

697

698

699

700

701

framework and its implementation as models and software. Ecology Letters, 20(5), 561-576. https://doi.org/10.1111/ele.12757

Paredes, D., Cayuela, L., Gurr, G. M., \& Campos, M. (2015). Single best species or natural enemy assemblages? a correlational approach to investigating ecosystem function. BioControl, 60(1), 37-45. https://doi.org/10.1007/s10526-014-9620-9

Paredes, D., Karp, D. S., Chaplin-Kramer, R., Benítez, E., \& Campos, M. (2019). Natural habitat increases natural pest control in olive groves: economic implications. Journal of Pest Science, 92(3), 1111-1121. https://doi.org/10.1007/s10340-019-01104-w

Paredes, Daniel, Cayuela, L., Gurr, G. M., \& Campos, M. (2015). Is Ground Cover Vegetation an Effective Biological Control Enhancement Strategy against Olive Pests? PLOS ONE, 10(2), e0117265. https://doi.org/10.1371/journal.pone.0117265

Pelekassis, C. D. (1962). A contribution to the study or nomenclature, taxonomy, biology, ecology and the natural parasitisation of the olive kernel borer, Prays oleae (Bernard) Lesne).

Posa, M. R. C., Sodhi, N. S., \& Koh, L. P. (2007). Predation on artificial nests and caterpillar models across a disturbance gradient in Subic Bay, Philippines. Journal of Tropical Ecology, 23(1), 27-33. https://doi.org/10.1017/S0266467406003671

QGIS Development Team (2018). QGIS Geographic Information System. Open Source Geospatial Foundation Project. http://qgis.osgeo.org.

R Core Team (2019). R: A language and environment for statistical computing. R Foundation for Statistical Computing, Vienna, Austria. 
702

703

704

705

706

707

708

709

710

711

712

713

714

715

716

717

718

719

720

721

722

Redlich, S., Martin, E. A., \& Steffan-Dewenter, I. (2018). Landscape-level crop diversity benefits biological pest control. Journal of Applied Ecology, 55(5), 2419-2428. https://doi.org/10.1111/1365-2664.13126

Rey Benayas, J. M., Meltzer, J., de las Heras-Bravo, D., \& Cayuela, L. (2017). Potential of pest regulation by insectivorous birds in Mediterranean woody crops. Plos One, 12(9), e0180702. https://doi.org/10.1371/journal.pone.0180702

Rey, P.J., (1993). The role of olive orchards in the wintering of frugivorous birds in Spain. Ardea 81, 151-160.

Rey, P. J. (2011). Preserving frugivorous birds in agro-ecosystems: lessons from Spanish olive orchards. Journal of Applied Ecology, 48(1), 228-237. https://doi.org/10.1111/j.1365-2664.2010.01902.x

Rey, P. J., Manzaneda, A. J., Valera, F., Alcántara, J. M., Tarifa, R., Isla, J., .. Ruiz, C. (2019). Landscape-moderated biodiversity effects of ground herb cover in olive groves: Implications for regional biodiversity conservation. Agriculture, Ecosystems \& Environment, 277, 61-73. https://doi.org/10.1016/J.AGEE.2019.03.007

Rosenberg, K. V., Dokter, A. M., Blancher, P. J., Sauer, J. R., Smith, A. C., Smith, P. A., ... Marra, P. P. (2019). Decline of the North American avifauna. Science, 366(6461), 120-124. https://doi.org/10.1126/science.aaw1313

Roslin, T., Hardwick, B., Novotny, V., Petry, W. K., Andrew, N. R., Asmus, A., ... Slade, E. M. (2017). Higher Predation Risk for Insect Prey at Low Latitudes and Elevations. Science, 356(6339), 742-744. 
723

724

725

726

727

728

729

730

731

732

733

734

735

736

737

738

739

740

741

742

743

744

Rusch, A., Chaplin-Kramer, R., Gardiner, M. M., Hawro, V., Holland, J., Landis, D., ... Bommarco, R. (2016). Agricultural landscape simplification reduces natural pest control: A quantitative synthesis. Agriculture, Ecosystems and Environment, 221, 198-204. https://doi.org/10.1016/j.agee.2016.01.039

Rusch, A., Delbac, L., Thiéry, D., \& Thi Ery, D. (2017). Grape moth density in Bordeaux vineyards depends on local habitat management despite effects of landscape heterogeneity on their biological control. Journal of Applied Ecology, 54, 1794-1803. https://doi.org/10.1111/1365-2664.12858

Storchová, L., \& Hořák, D. (2018). Life-history characteristics of European birds. Global Ecology and Biogeography, 27(4), 400-406. https://doi.org/10.1111/geb.12709

Tscharntke, T., Karp, D. S., Chaplin-Kramer, R., Batáry, P., DeClerck, F., Gratton, C., ... Zhang, W. (2016). When natural habitat fails to enhance biological pest control - Five hypotheses. Biological Conservation, 204, 449-458. https://doi.org/10.1016/J.BIOCON.2016.10.001

Villa, M., Santos, S. A. P., Mexia, A., Bento, A., \& Pereira, J. A. (2016). Ground cover management affects parasitism of Prays oleae (Bernard). Biological Control, 96, 7277. https://doi.org/10.1016/J.BIOCONTROL.2016.01.012

Wilman, H., Belmaker, J., Simpson, J., de la Rosa, C., Rivadeneira, M. M., \& Jetz, W. (2014). EltonTraits 1.0: Species-level foraging attributes of the world's birds and mammals. Ecology, 95(7), 2027-2027. https://doi.org/10.1890/13-1917.1

Winqvist, C., Bengtsson, J., Aavik, T., Berendse, F., Clement, L. W., Eggers, S., ... Bommarco, R. (2011). Mixed effects of organic farming and landscape complexity on 
farmland biodiversity and biological control potential across Europe. Journal of Applied Ecology, 48(3), 570-579. https://doi.org/10.1111/j.1365-2664.2010.01950.x W. (2017). Video monitoring of brown planthopper predation in rice shows flaws of sentinel methods. Scientific Reports, 7(1), 42210. https://doi.org/10.1038/srep42210

Table 1. Results from Bayesian hierarchical models that show the estimated effect of landscape heterogeneity (scale of $1 \mathrm{~km}$ radius) on the abundance/richness of insectivorous birds. The table displays the posterior mean, standard error, 95\% credible intervals, and probability of beta being higher than 0 . Results are in the log scale. In bold, models with a posterior probability over $90 \%$ of beta (slope) being positive/negative. SNA $=$ Semi-

Natural Area, $\mathrm{ED}=$ Edge Density, $\mathrm{PD}=$ Shannon diversity, $\mathrm{PR}=$ Patch richness, $\mathrm{OC}=$ Area of olive orchards, NND = Distance to Nearest Neighbor.

\begin{tabular}{|c|l|c|c|c|c|c|}
\hline Model & Fixed factors & Posterior beta & Standard & 95\% LCI & 95\% UCI & Prob. \\
& (beta/ slope ) & estimated & error & & & $\boldsymbol{\beta}>\mathbf{0}$ \\
\hline \multirow{3}{*}{$\begin{array}{c}\text { Abundance } \\
\text { insectivorous } \\
\text { birds }\end{array}$} & SNA & 0.07 & 0.10 & -0.12 & 0.27 & 0.79 \\
\cline { 2 - 7 } & ED & $\mathbf{0 . 1 4}$ & $\mathbf{0 . 1 0}$ & $\mathbf{- 0 . 0 5}$ & $\mathbf{0 . 3 5}$ & $\mathbf{0 . 9 4}$ \\
\cline { 2 - 8 } & PD & -0.18 & 0.34 & -0.88 & 0.50 & 0.27 \\
\cline { 2 - 8 } & OC* & 0.06 & 0.08 & -0.10 & 0.23 & 0.81 \\
\cline { 2 - 8 } & NND* & 0.11 & 0.23 & -0.36 & 0.56 & 0.29 \\
\hline \multirow{2}{*}{$\begin{array}{c}\text { Richness } \\
\text { insectivorous }\end{array}$} & SNA & 0.04 & 0.03 & -0.18 & 0.25 & 0.66 \\
\cline { 2 - 8 } & ED & 0.07 & 0.07 & -0.07 & 0.21 & 0.84 \\
\hline
\end{tabular}


bioRxiv preprint doi: https://doi.org/10.1101/2020.03.07.981845; this version posted March 8,2020 . The copyright holder for this preprint (which was not certified by peer review) is the author/funder, who has granted bioRxiv a license to display the preprint in perpetuity. It is made available under aCC-BY-NC-ND 4.0 International license.

758

759

760

761

762

763

764

765

766

\begin{tabular}{|c|c|c|c|c|c|c|}
\hline \multirow[t]{4}{*}{ birds } & PD & 0.29 & 0.17 & -0.06 & 0.66 & 0.96 \\
\hline & PR & 0.02 & 0.06 & -0.10 & 0.13 & 0.64 \\
\hline & OC* & -0.06 & 0.05 & -0.15 & 0.03 & 0.91 \\
\hline & NND* & -0.11 & 0.04 & -0.20 & -0.02 & 0.99 \\
\hline \multirow{3}{*}{ Abundance } & SNA & 0.07 & 0.08 & -0.09 & 0.24 & 0.83 \\
\hline & ED & 0.15 & $\mathbf{0 . 0 7}$ & 0.02 & 0.28 & 0.98 \\
\hline & PD & -0.04 & 0.09 & -0.23 & 0.14 & 0.29 \\
\hline insectivorous & PR & 0.07 & 0.09 & -0.11 & 0.26 & 0.82 \\
\hline \multirow[t]{2}{*}{ birds } & $\mathrm{OC}^{*}$ & -0.01 & 0.09 & -0.19 & 0.16 & 0.55 \\
\hline & NND* & 0.00 & 0.09 & -0.18 & 0.18 & 0.49 \\
\hline \multirow{3}{*}{ Richness forest } & SNA & 0.07 & 0.06 & -0.05 & 0.20 & 0.91 \\
\hline & ED & 0.12 & 0.05 & 0.01 & 0.22 & 0.98 \\
\hline & PD & 0.05 & 0.07 & -0.09 & 0.20 & 0.81 \\
\hline insectivorous & PR & 0.07 & 0.07 & -0.07 & 0.22 & 0.86 \\
\hline \multirow{2}{*}{ birds } & $\mathrm{OC}^{*}$ & -0.05 & $0-06$ & -0.18 & 0.08 & 0.82 \\
\hline & NND* & $-\mathbf{0 . 0 7}$ & 0.06 & -0.20 & 0.05 & 0.91 \\
\hline
\end{tabular}

*Because OC and NND are expected to affect negatively the abundance and richness, probabilities represent the hypothesis of beta being lower than 0 . 
Table 2. Results from Bayesian multilevel models that show the estimated effect of site

771 (close or far from semi-natural patch) and treatment (excluded-control branch) on total

772 damage observed to olive trees. The table displays the posterior mean, standard error, $95 \%$

773 credible interval, and $\mathrm{R}^{\wedge}$ statistic for each parameter of models with a varying intercept by

774 locality and tree. In bold, factor levels with a $\beta$ parameter higher or lower than 0

775 (probability of 95\%).

\begin{tabular}{|c|c|c|c|c|c|c|}
\hline Model & Fixed factors & $\begin{array}{c}\text { Posterior } \\
\text { intercepts and } \\
\text { betas }\end{array}$ & $\begin{array}{l}\text { Standard } \\
\text { error }\end{array}$ & $\begin{array}{l}95 \% \\
\mathrm{LCI}\end{array}$ & $\begin{array}{l}95 \% \\
\mathrm{UCI}\end{array}$ & $\mathrm{R}^{\wedge}$ \\
\hline \multirow{3}{*}{$\begin{array}{l}\text { P. oleae } \\
\text { damage }\end{array}$} & $\begin{array}{l}\text { Intercept } \\
\text { (Control branch and close to patch) }\end{array}$ & 0.14 & 0.03 & 0.08 & 0.20 & 1.00 \\
\hline & Excluded branch & -0.01 & 0.01 & -0.03 & 0.01 & 1.00 \\
\hline & Far from patch & 0.04 & 0.01 & 0.02 & 0.06 & 1.00 \\
\hline \multirow{3}{*}{$\begin{array}{l}\text { B. oleae } \\
\text { damage }\end{array}$} & $\begin{array}{l}\text { Intercept } \\
\text { (Control branch and close to patch) }\end{array}$ & 0.34 & 0.07 & 0.20 & 0.48 & 1.01 \\
\hline & Excluded branch & -0.10 & 0.03 & -0.16 & -0.04 & 1.00 \\
\hline & Far from patch & 0.05 & 0.03 & -0.01 & 0.12 & 1.00 \\
\hline \multirow{3}{*}{$\begin{array}{l}\text { Herbivore } \\
\text { damage }\end{array}$} & $\begin{array}{l}\text { Intercept } \\
\text { (Control branch and close to patch) }\end{array}$ & 0.60 & 0.09 & 0.43 & 0.78 & 1.01 \\
\hline & Excluded branch & -0.05 & 0.02 & -0.09 & -0.01 & 1.00 \\
\hline & Far from patch & 0.06 & 0.02 & 0.02 & 0.10 & 1.00 \\
\hline
\end{tabular}




\begin{tabular}{|c|l|c|c|c|c|c|}
\hline \multirow{2}{*}{ Total } & $\begin{array}{l}\text { Intercept } \\
\text { damage }\end{array}$ & 0.47 & 0.04 & 0.37 & 0.55 & 1.00 \\
& (Control branch and close to patch) & & & & & \\
\cline { 2 - 7 } & Excluded branch & $\mathbf{- 0 . 0 4}$ & $\mathbf{0 . 0 1}$ & $\mathbf{- 0 . 0 7}$ & $\mathbf{- 0 . 0 2}$ & $\mathbf{1 . 0 0}$ \\
\cline { 2 - 7 } & Far from patch & $\mathbf{0 . 0 5}$ & $\mathbf{0 . 0 1}$ & $\mathbf{0 . 0 3}$ & $\mathbf{0 . 0 8}$ & $\mathbf{1 . 0 0}$ \\
\hline
\end{tabular}
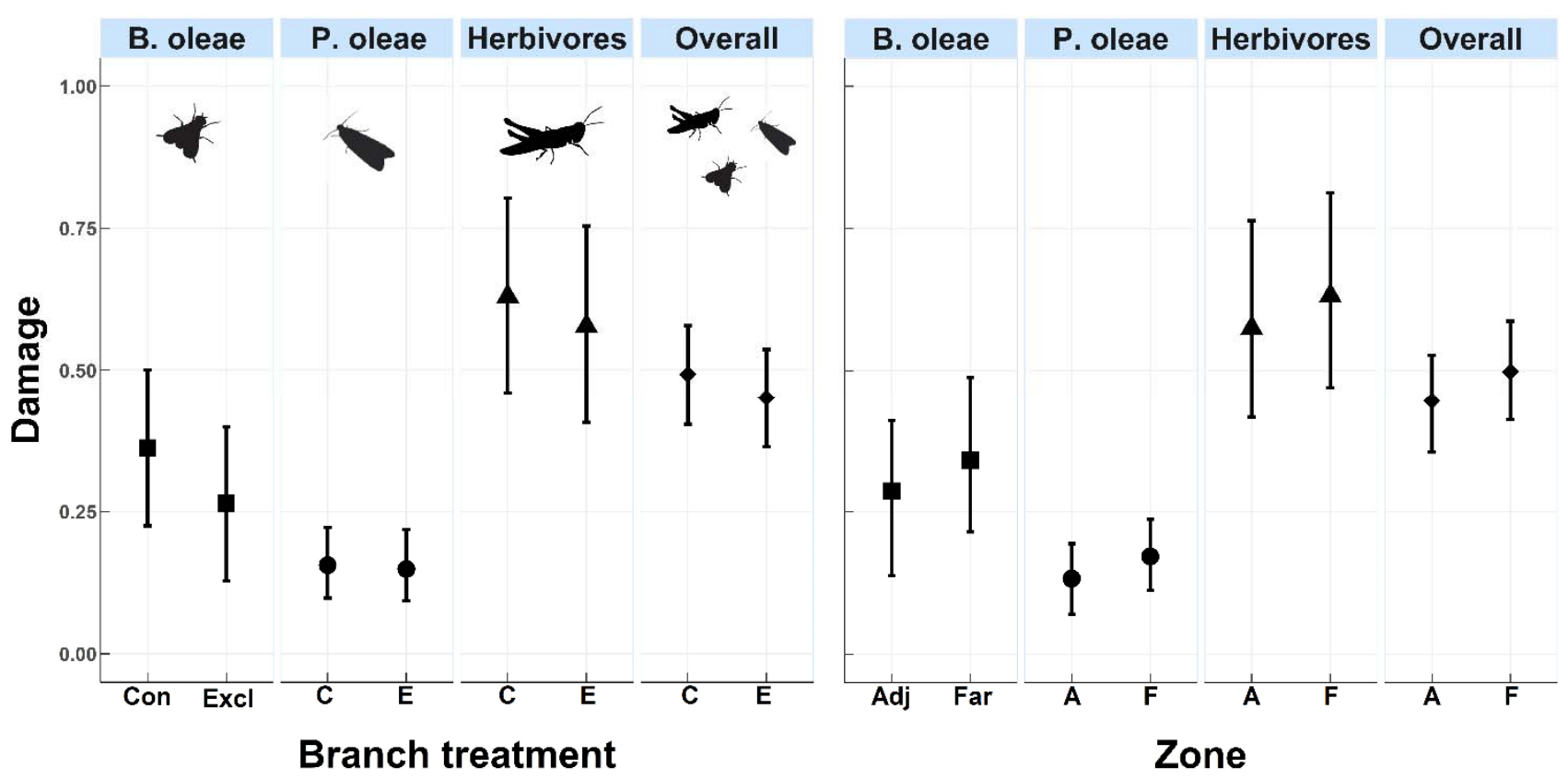

777

778 Figure 1. Back-transformed predicted damage (proportion) produced by P. oleae, B. oleae,

779 Herbivores and Overall (cumulated) and its variation across treatments (Control Vs.

780 Excluded branch) and Zone (Adjacent to semi-natural patch =Adj. Vs. olive orchard matrix,

781 far from semi-natural patches= Far). Solid symbols show predicted posterior mean and

782 whiskers $95 \%$ credible intervals. 
bioRxiv preprint doi: https://doi.org/10.1101/2020.03.07.981845; this version posted March 8, 2020. The copyright holder for this preprint (which was not certified by peer review) is the author/funder, who has granted bioRxiv a license to display the preprint in perpetuity. It is made available under aCC-BY-NC-ND 4.0 International license.

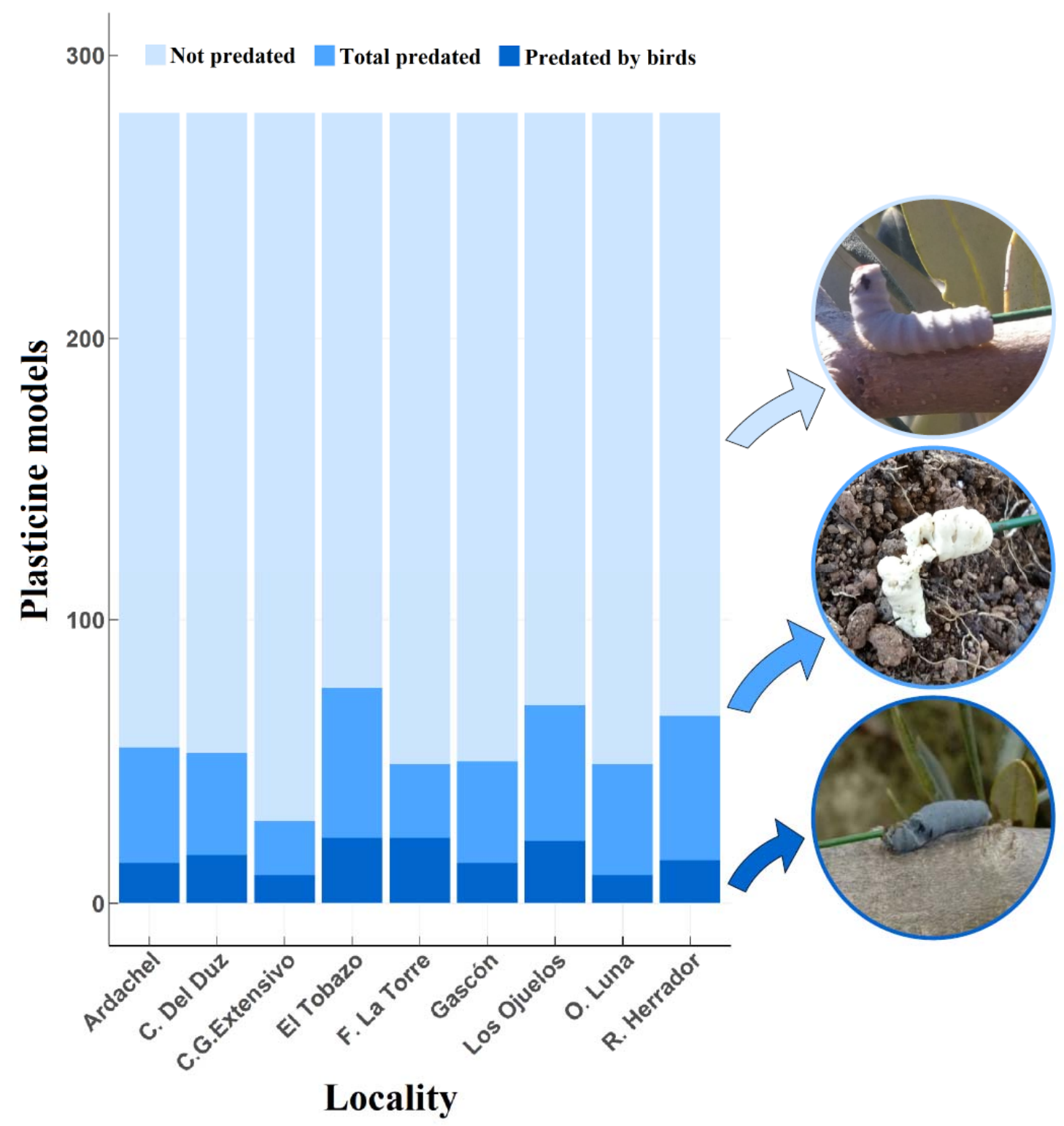

786 Figure 2. Observed number of plasticine models attacked by birds (dark blue), by other

787 animals, mainly ants (clear blue) and not attacked (light blue). 